\title{
ANÁlISIS DE EDIFICACIONES DE INTERÉS CULTURAL- ARQUITECTÓNICO DEL DISTRITO CENTRAL DE HEREDIA: PLAN DE PROTECCIÓN DE LA ZONA URBANA HISTÓRICA
}

\begin{abstract}
Resumen
El distrito central de Heredia ha sufrido una gran transformación a nivel urbano en las últimas décadas. Esto se refleja en el creciente desarrollo comercial y habitacional de la zona, ya que tanto la fuerte presión por la disponibilidad del suelo como los intereses de tipo económico y de rentabilidad en este distrito, han llevado a la extinción de inmuebles de interés histórico-arquitectónico aún no declarados como patrimonio por el Estado.

Es, por lo tanto, necesario trabajar en un aporte histórico, arquitectónico y urbano orientado al reconocimiento de inmuebles de valor patrimonial y algunos de los elementos que caracterizan la identidad cultural de la zona. Esto permitirá establecer una serie de estrategias urbanas, enfocadas a la preservación del patrimonio, contenidas en un Plan de Protección.
\end{abstract}

Palabras clave: Plan de protección, Arquitectura, Gestión del Patrimonio, Centro histórico.

\begin{abstract}
Heredia's central district has undergone a major urban transformation in recent decades. This is reflected in the growing commercial and residential development in the area, because of the strong pressure for land availability, as well as economic interests and profitability in this district, both have led to the extinction of properties of historical and architectural interest not yet under state protection.

It is therefore necessary to work in a historical, architectural and urban-oriented contribution to identify the properties of heritage value and some of the elements that characterize the cultural identity of the area. This will help establish a series of urban strategies, focused on heritage preservation, contained in a Protection Plan.
\end{abstract}

Key Words: Protection plan, Architecture, Heritage management, Historical center.

Angie Castro Elizondo. Graduada de la carrera de Arquitectura del Instituto Tecnológico de Costa Rica. Miembro fundadora del Centro Internacional para la Conservación del Patrimonio Costa Rica (CICOP Costa Rica). Miembro del equipo técnico del Plan Nacional de Desarrollo Urbano de la Gran Área Metropolitana 2013 (Plan GAM 2013). Correo electrónico: angiecstr@outlook.com
"La herencia del pasado, en cualquiera de sus manifestaciones, es una joya invaluable que debe ser aquilatada y guardada con orgulloso celo. Ella constituye la esencia de nuestra nacionalidad, el alma del cuerpo colectivo, la razón misma del progreso...

Es por esto que un pueblo que destruye y desprecia su legado ancestral, se condena irremisiblemente a no pesar en la balanza de la historia y a ser barrido de la memoria de los verdaderos hombres." 


\section{Problema}

El rápido proceso de expansión de las ciudades genera presión sobre el territorio de estas y las lleva muchas veces a límites que es no son capaces de soportar. Es por este motivo que se gestan planes de Ordenamiento Territorial, como el Plan Nacional de Desarrollo Urbano de la Gran Área Metropolitana 2013-2030 (Plan GAM 2013-2030). Este programa desarrolla un modelo de crecimiento que busca detener el proceso de expansión de la mancha urbana, aprovechando al máximo los sitios ya urbanizados.

El Plan GAM es una herramienta necesaria para el problema del crecimiento sin control de la Gran Área Metropolitana pero, ¿qué pasa con el descontrol urbano en los puntos específicos de esa región? El plan GAM reconoce la ciudad de Heredia como histórica; sin embargo, también anota que el centro de la ciudad funciona principalmente como una zona comercial, y esta transformación de los usos es la que pone en peligro los inmuebles históricos.

Heredia y su cantón central son cada día más comerciales, por lo cual se incrementa el valor de los terrenos y aumenta, a la vez, el interés de sus propietarios por hacerlos disponibles para entregarlos al mejor postor.

El centro histórico forma parte de una estructura mayor — urbana, socioeconómica y de uso- que genera gran presión sobre él. La falta de un plan regulador, la ausencia de un acceso constante de la información y la historia de la ciudad, han llevado al olvido la importancia del cantón central de la ciudad de Heredia y lo que él encierra.

Dentro de la ciudad se encuentran edificios y conjuntos que constituyen importantes puntos de desarrollo. Estos inmuebles forman un sitio estratégico para la recuperación y uso de la ciudad pero, para resguardar un centro histórico, solamente la protección de los edificios como elementos puntuales se vuelve insuficiente.

La ciudad de Heredia, específicamente, ha visto cómo diversas construcciones han sido demolidas por sus propietarios de un día a otro, con la extraña finalidad de evitar la declaratoria de patrimonio histórico, así como las actividades y los costos económicos que ésta conlleva.

La búsqueda del proyecto GAM no radica en volver a la ciudad de Heredia una zona urbana inalterable, sino en ayudar a que quienes viven en ella entiendan la importancia de su historia, sus edificios y manifiesten nuevamente el orgullo que sienten de pertenecer a esta ciudad.

\section{Protección integral: El valor de conjunto urbano evoluciona sobre las intervenciones específicas}

La fuerte presión por la disponibilidad del suelo en el distrito central de Heredia ha llevado a la extinción de inmuebles de interés histórico-arquitectónico que aún no han sido declarados como patrimonio por el Estado. Edificaciones que fueron testigos de importantes eventos históricos y construidas con sistemas ya en desuso, son demolidas por sus propietarios para dar paso a actividades comerciales como tiendas o parqueos (Ver ilustración 1).

Costa Rica cuenta con una Ley sobre el Patrimonio Histórico Arquitectónico, la Ley 7555 que rige desde el año 1995. El objetivo de esta ley, como se menciona en el artículo número uno, es: "La conservación, la protección y la preservación del patrimonio histórico-arquitectónico de Costa Rica" (Presidente de la República y el Ministro de Cultura Juventud y Deportes, 2005). Sin embargo, esta ley presenta grandes carencias en materia de resguardo de conjuntos y también en la sección de gestión, innovación y planes de protección. 
Las declaratorias patrimoniales de inmuebles nacieron como una opción para proteger la cultura y la arquitectura. Con ellas se ha logrado una mayor participación de las personas en la protección de las edificaciones. No obstante, estos esfuerzos por salvaguardar el Patrimonio Nacional no han sido suficientes. Los nuevos modos de vida hacen que las ciudades vayan tomando nuevas formas y en ellas los nuevos usos deben adaptarse a la morfología de la ciudad, a su simbolismo y al patrimonio ya existente.

La particularidad de las zonas urbanas históricas - que revelan las principales características de la conformación y desarrollo de las ciudades- ha incentivado su manejo y protección no solo como una forma de memoria, sino también como un área de estudio en el urbanismo actual. Hoy en día se renueva y rehabilita, no solo se restaura.

En nuestro país, la gestión para conservar conjuntos patrimoniales apenas empieza a promoverse. Sin embargo, importantes avances se han realizado en el mundo en las últimas décadas para determinar los lineamientos de trabajo y protección de los sitios histó-

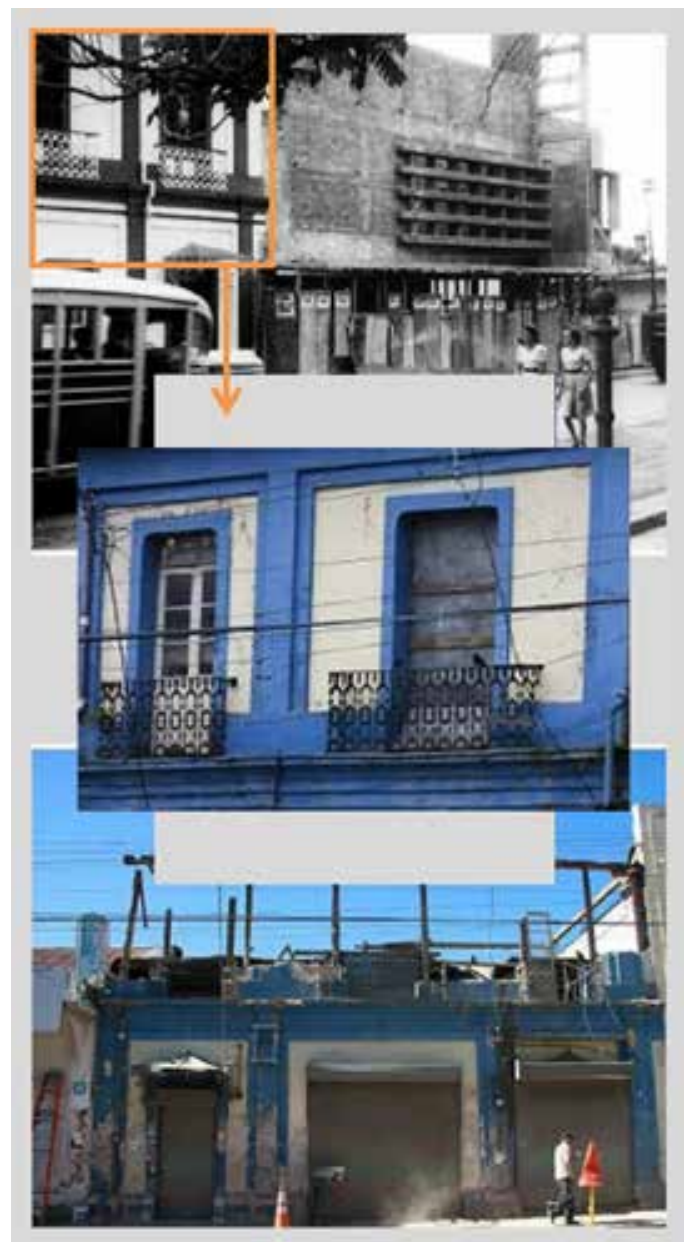
ricos. Esto permite comparar experiencias y definir necesidades, lo cual genera gran cantidad de información para dirigir el camino. A continuación se enumeran algunos de los documentos y acontecimientos que han aportado en este sentido.

La Carta de Atenas, de 1931, indica que se debe brindar especial atención al paisaje urbano, ya que es el contexto en el que están insertos los elementos y, por lo tanto, posee características que deben ser protegidas.

Durante la Segunda Guerra Mundial se destruyeron ciudades y pueblos enteros, por lo que fue necesario estudiar las ciudades remanentes, con el fin de suplir las necesidades de vivienda del momento. Ante esta circunstancia, las estrategias de protección toman dos caminos: por un lado, los planes cuyo único fin era rescatar centros históricos independientemente de las futuras actividades y, por otro lado, los planes que buscaban rescatar los inmuebles subsistentes y plantear un plan de ciudad con miras a un futuro próspero que protegiera los edificios.

La Convención de la Haya hace un aporte importante al indicar la importancia de los inmuebles como partes de un todo y no como objetos aislados.

En el Congreso de Gubbio se muestran los resultados obtenidos de los primeros planes urbanos en áreas históricas que fueron puestos en acción en Italia. Este es el inicio de un urbanismo histórico impulsado por los Estados.

La Carta de Venecia, de 1964, es considerada como el documento de mayor relevancia con respecto a la preservación del patrimonio. Entre otros planteamientos, el texto indica que es responsabilidad de toda la sociedad el resguardar los sitios
Ilustración 1. Comparación antes y después del Edificio de los Cafetaleros. 
históricos, abriendo el espectro de la protección a la totalidad de la comunidad.

Las Normas de Quito, de 1967, intervienen desde la perspectiva de los países latinoamericanos, por lo cual son de vital importancia, dado que en este documento se consideran las diferencias regionales. De esta forma, se observa que es necesario ser conscientes de que nuestras ciudades tienen escalas muy diferentes a las de las ciudades europeas. Además, este documento indica que hay un elemento clave en la revalorización de los centros históricos y es la educación.

Con otros documentos como la Carta del Restauro o la Confrontación de Boloña, se amplía el concepto de urbanismo histórico al considerar, no solo la parte más antigua del centro urbano, sino también las zonas más recientes generadas por las necesidades de crecimiento.

La Declaración de Ámsterdam profundiza en lo que conocemos como 'Patrimonio modesto'. Y la Carta de Burra - Carta del ICOMOS Australia para Sitios de Significación Cultural- es un documento de vital importancia que permite, entre otros, unificar los conceptos de 'Conservación', 'Mantenimiento', 'Preservación' y 'Restauración', entre otros.

La Carta de Washington insiste en la participación y el compromiso de la comunidad para la conservación. Asimismo indica que los planes de salvaguarda deben tener un fin cívico y social siempre mayor, sobre la comodidad y la vivencia de las ciudades por sus habitantes.

Retomando de nuevo el trabajo realizado en nuestro país, la Ley 7555 o Ley de Patrimonio Histórico Arquitectónico de Costa Rica, recordemos, establece que sus objetivos son "la conservación, la protección y la preservación del patrimonio histórico-arquitectónico de Costa Rica" y que, tanto inmuebles de propiedad privada como públicos, pueden llegar a ser declarados como Patrimonio. Entre los principales problemas que presenta la ley, es que es muy vaga con respecto a sus directrices, lo cual sumado a la falta de interés de la comunidad nacional, ha llevado a generar una oposición casi absoluta para las declaratorias de los inmuebles.

Con respecto a la protección de zonas urbanas históricas la ley 7555 indica que, cuando se trata de un conjunto, sitio o centro histórico se debe cumplir con los planes reguladores promulgados, según la Ley de Planificación Urbana, № 4240. Esta ley indica que dentro de los planes reguladores se deben contemplar las zonas que puedan y deban ser sometidas a la conservación, pero no da mayor explicación sobre las características de estos lugares. $\mathrm{Y}$, lamentablemente, la ciudad de Heredia y su gobierno local, hasta la fecha no han alcanzado un consenso ni elaborado un Plan Regulador para ese territorio.

La finalidad de los planes de protección es potenciar y garantizar la conservación de los valores arquitectónicos y de contexto de las zonas urbanas históricas. Pero además buscan asegurar la permanencia de la memoria al incluir a las comunidades y las estrategias de acción y educación, dentro de los lineamientos que plantean.

Uno de los principales detractores que han tenido los planes de manejo es el mercado del territorio. En el caso específico de Heredia es notable la falta de un Plan Regulador. Por otra parte, es posible ver dos fenómenos que afectan las principales zonas históricas del país: el primero es que hacen falta incentivos y beneficios que puedan disfrutar los propietarios de los inmuebles históricos para incentivar su participación en el resguardo de las construcciones; el segundo fenómeno es que no se aplican las sanciones a quienes violentan los inmuebles. Además las infracciones son tan pequeñas que quienes realizan estos daños no les dan mayor importancia a sus acciones, porque saben que no habrá consecuencias a largo plazo que los puedan afectar.

Podría decirse que la protección del patrimonio es un derecho fundamental, por lo tanto se han violentado los derechos de los costarricenses al atentar contra los 
valores de la ciudad y al no buscar los mecanismos de protección adecuados para estas zonas y sus elementos.

La realidad política es compleja pero la presión social es poderosa. Si se empieza el trabajo con los entes culturales y las instituciones educativas y se planifican las acciones para tomar, las mejoras se podrán hacer una realidad.

\section{Planteamiento del Plan de Protección Urbano}

El principal objetivo del Plan de Protección en el Distrito Central del Cantón de Heredia fue definir las jerarquías patrimoniales de esa zona y plantear las estrategias urbano-arquitectónicas que permitan la revaloración, rescate de la historia del pueblo herediano y prevención de la destrucción del Patrimonio Histórico-Arquitectónico del lugar (Castro Elizondo, 2014).

La investigación se conforma por dos ejes temáticos. En el primero se incluye todo lo referente a recopilación, interpretación y análisis de información; este eje tiene como objetivo comprender la importancia de la zona de estudio para los ciudadanos y, en general, para el desarrollo de la ciudad. Por otra parte, el segundo eje temático lo constituye el desarrollo del plan de protección propiamente dicho.

Este estudio identificó, primeramente, diferentes zonas de la ciudad, los inmuebles de valor patrimonial histórico-arquitectónico y las medidas necesarias para proteger el centro histórico de la ciudad.

Paralelamente, el proyecto busca brindar las directrices para proteger el patrimonio herediano como un conjunto y no sólo a casos aislados. Para que las construcciones estén protegidas efectivamente es necesario plantear tratamientos especiales según cada zona para, así, asegurar un funcionamiento y desarrollo integral de la ciudad.

La clave del éxito en todo plan que busque la valorización de un centro histórico, dependerá de qué tanto se incorpore a la comunidad actual de esta zona dentro de estos planes y de cuánto se les permita a los ciudadanos revalorar su ciudad. Sólo así se logrará afianzar los sentimientos de orgullo que se han ido perdiendo y asegurar una comunidad unida que permita darle permanencia al centro histórico.

Por tal motivo, es necesario brindar la información técnica sobre el mantenimiento de los inmuebles $y$, además, trabajar en el apego emocional y cultural que representan estas edificaciones a nivel de comunidad. De esta forma, la resistencia a mantener los inmuebles por parte de los propietarios sería menor, en tanto se estaría protegiendo el objeto no por sí mismo sino por lo que éste representa.

La importancia de este proyecto radica en ser una herramienta necesaria para la preservación puesto que ofrece estrategias para generar incentivos culturales, promueve la recuperación de la identidad, plantea campañas de información técnica al alcance de todos y brinda lineamientos urbanos para el mejoramiento y desarrollo que la ciudad tanto necesita.

\section{Evolución urbana del cantón central de Heredia}

Con el propósito de comprender el contexto histórico en el que se conformó el cantón central de Heredia, y más específicamente los elementos arquitectónicos relevantes para el estudio, se realizó una reconstrucción de la historia y de la evolución urbana del lugar.

La evolución de la ciudad de Heredia se encuentra dividida en cuatro momentos. La primera parte va desde 1560 a 1810 y muestra el nacimiento de la población de Cubujuquí, también Ilamada Villa de la Inmaculada Concepción de Heredia. De esa etapa existen algunos datos generales y varios hechos que marcan el inicio 


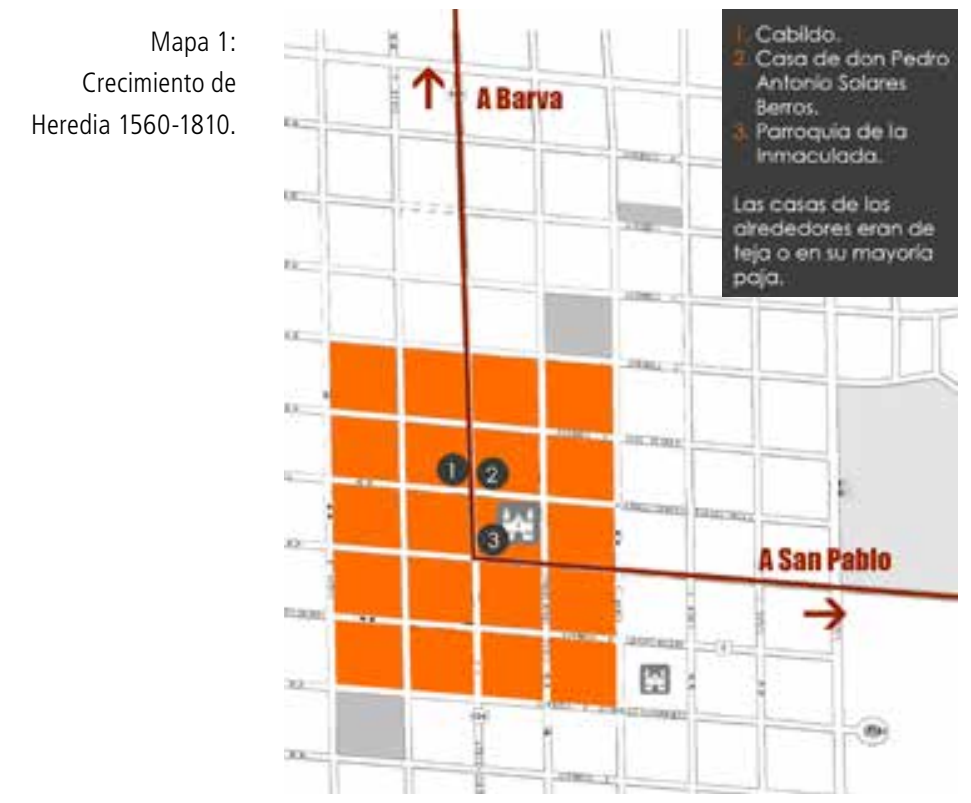

de la actual Ciudad de Heredia, entre ellos el decreto que ordenaba habitar Cubujuquí a los pobladores del Valle de Barva, la construcción del Templo Parroquial y la obtención de éste poblado el título de Villa.

La segunda etapa de su historia va desde 1810-1824 e inicia con la descripción de Heredia por parte del Gobernador de Costa Rica, el señor Tomás Acosta. En ella se caracteriza a la ciudad con una hermosa plaza y cuyos habitantes ocupan diez calles de norte a sur igualmente de este a oeste, cada calle con diez manzanas de cien varas de frente y cada manzana divida en cuatro solares habitados (Rodríguez Argüello, 1998). Esta etapa termina con la obtención del título de Ciudad.

Es notable una particularidad del trazado de la ciudad de Heredia: "el ángulo que se formaba entre los caminos que iban y venían de Barva hasta San Pablo, medía unos grados más que un ángulo recto" (Ellenberg, 1984: 253). La diferencia era tan pequeña que se continuó la construcción de las cuadras a los lados de estos caminos.

Estas variaciones en el trazado de la ciudad no fueron significativas durante esa época, porque las propiedades no eran colindantes y, conforme la ciudad fue creciendo, simplemente no se hicieron modificaciones al plano de la ciudad sino que las construcciones se fueron adecuando a su forma particular. Estos caminos ya existentes, le dieron forma a la actual Ciudad de Heredia.

La tercera parte comprende el periodo de 1825 a 1849 y de ella se estudian los hechos que poco a poco fueron dando forma a la zona urbana que conocemos. Ya

en esta etapa se empiezan a ver una serie de construcciones y personajes importantes para la identidad herediana, como la casa de Nicolás Ulloa o la Casa de Braulio Morales.

Este periodo finaliza cuando se le otorga a Heredia el estatus de cantón y se le asignan siete distritos, según la nueva distribución administrativa del país, que ahora era una República.

La última sección muestra cómo se fue desarrollando la ciudad de Heredia en ésta nueva estructura política. La cronología inicia en 1850 y acaba en 2014, cuando se inicia un proceso de "modernización de la ciudad".

Esta sección muestra cómo creció Heredia y permite ver de qué forma se ha transformado, al igual que en todas las ciudades del mundo. Sin embargo, como en muchas otras partes, también 
se ha descuidado, lo que provocó la destrucción de los inmuebles que una vez fueron orgullo del pueblo y hoy sería un honor poder conservarlos.

En el Mapa 3 se muestra la ubicación de las principales construcciones representativas de la ciudad de Heredia desde su fundación y se realiza una zonificación de los sectores que fueron vitales para su

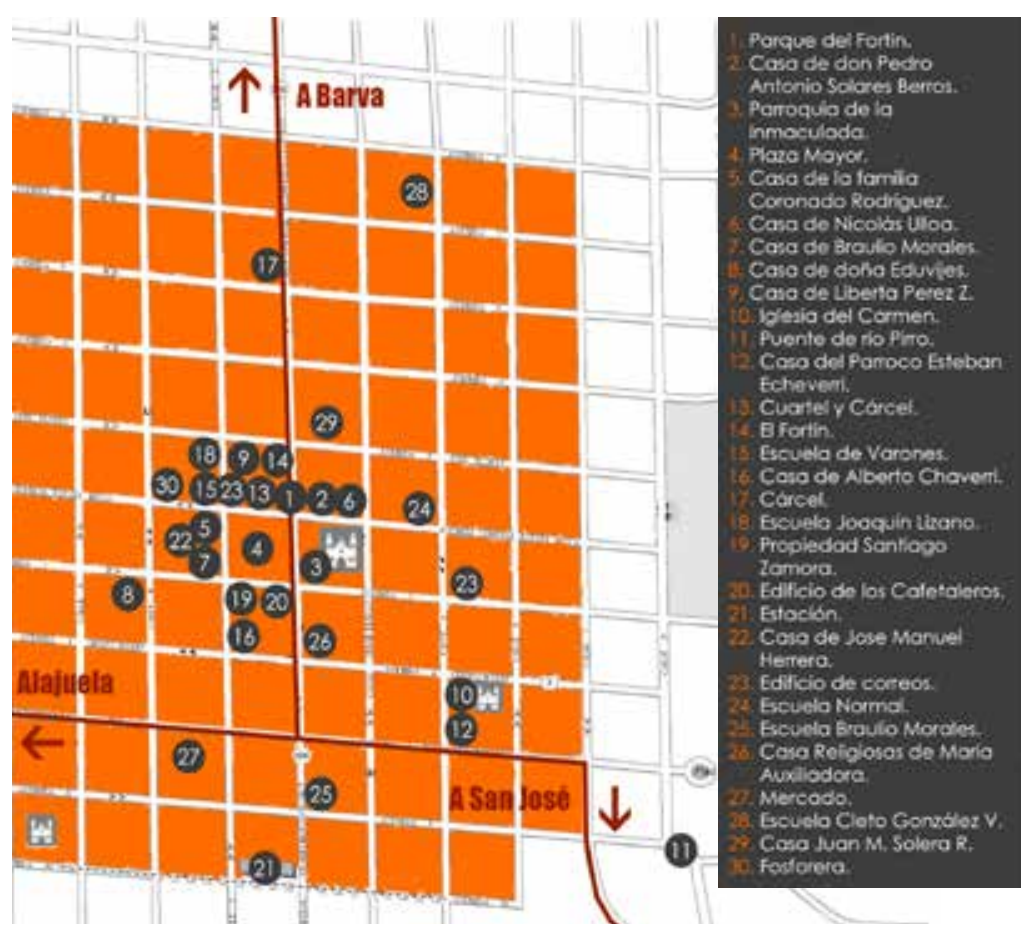
Mapa 3: Crecimiento de Heredia 1850-1950. desarrollo.

Desde que Heredia empezó a percibirse como "Ciudad dormitorio", comenzó a sufrir un paulatino desgaste infraestructural. Sin embargo, no se pueden descuidar todos sus elementos arquitectónicos, debido a que conforman un conjunto urbano histórico de gran interés cultural

Como todas las ciudades del mundo, Heredia ha sufrido un proceso de alteración pero, como en muchas otras también, se ha descuidado mucho, lo que ha permitido la destrucción de los inmuebles que una vez fueron orgullo del pueblo y hoy debería ser un honor poder conservarlos.

Heredia inició como parte de una red de poblados interconectados y creció tanto como sus límites se lo permitieron. Hoy Heredia es un centro de cultura y una ciudad próspera, pero todos los elementos que hacen de este conjunto urbano un lugar de historia se están perdiendo y eso no puede permitirse.

\section{Inventario de inmuebles}

Con el fin de definir las características particulares de los inmuebles, así como las jerarquías que definen a las zonas por delimitar y que caracterizan al distrito central del cantón de Heredia, se realizó un inventario de inmuebles.

Este inventario, sumado a las zonas establecidas que poseen mayor existencia de inmuebles históricos, permitió establecer un Centro Histórico en el distrito central del cantón de Heredia.

La totalidad del Centro Histórico se cataloga, según la clasificación descrita en las Normas de Quito, como una zona de protección del paisaje urbano. Y se delimita dentro de ella tres sectores especiales:

- Dos zonas de protección o respeto: Sector Norte (1) y Sector Sur (3).

- Una zona de protección rigurosa: Sector Central (2).

A partir de todo esto y considerando que, a través de los años, son muchas las propiedades que han sido destruidas y de las que no ha que quedado registro, sur- 

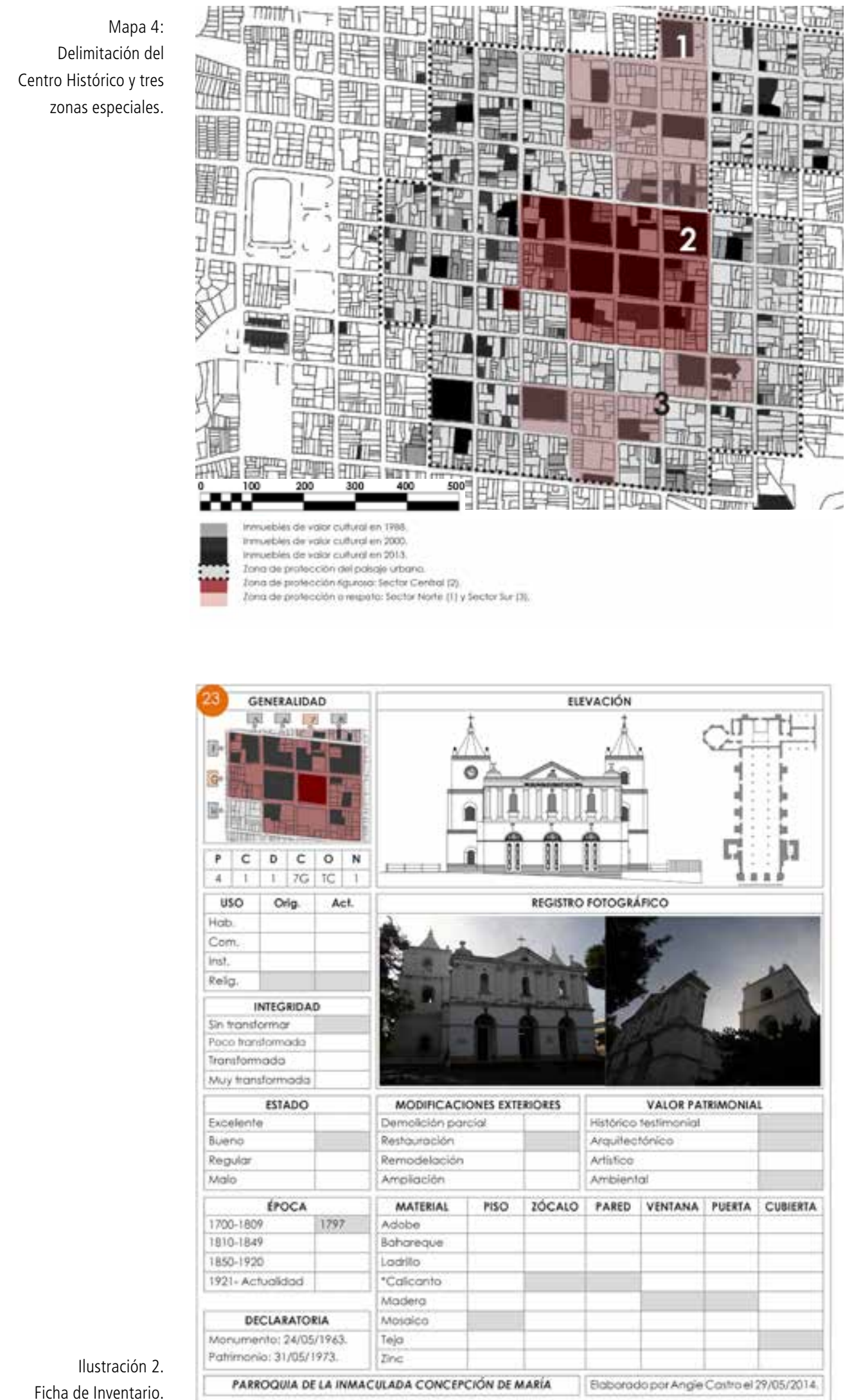

ge la necesidad de dejar una memoria, si bien básica, no por ello menos necesaria, que permanezca como muestra de la arquitectura de la zona.

Por este motivo se decide:

- Elaborar un registro fotográfico básico de todos los inmuebles "Grado II" inmersos zona de protección del paisaje, y de todos los inmuebles "Grado I" que se encuentran fuera de los sectores establecidos.

- Levantar un inventario de todos los inmuebles "Grado I" pertenecientes a los sectores Norte (1), Central (2) y Sur (3).

Las fichas de inventario permitieron determinar las características y condiciones de la arquitectura representativa existente. Los datos de uso indican que, efectivamente, hay un efecto de migración de los habitantes que da paso a la función comercial.

El proyecto plantea que la compatibilidad 
entre el uso comercial y el rescate del patrimonio cultural es alcanzable si se planean adecuadamente los cambios necesarios de realizar, de forma tal que se aumente el valor de los inmuebles $y$, de esta manera, disminuir el descuido que tanto los afecta. Los usos compatibles virtualmente no han sido explorados y deben de gestionarse. De hecho, las modificaciones realizadas en la gran mayoría de los inmuebles responden a necesidades espaciales inherentes al cambio de usos.

El $54 \%$ de los inmuebles de la zona presentan pocas transformaciones en sus diferentes variables, lo cual indica que no son una mayoría quienes se han arriesgado a intervenir las construcciones. Sin embargo, esto no refleja necesariamente aspectos positivos, pues lo que han hecho muchos de los propietarios de los inmuebles a través del tiempo ha sido, sencillamente, demoler sus propiedades.

En los inmuebles en condición regular, sí se pueden hacer transformaciones que permitan recuperar un estado estético más aceptable. Sin embargo, el objetivo de este proyecto no es crear una ciudad inalterable, sino que busca darle un mantenimiento preocupado a estos inmuebles para que se pueda obtener espacios de mejor calidad.

Curiosamente, se encontraron altos valores de restauración; sin embargo, esto puede inducir a error pues esto no es general, sino que muchos de estos edificios son los más pintorescos y pertenecen al Estado, por lo que se trabaja mucho en ellos. El problema es que no ha existido preocupación por proteger los inmuebles de menor escala. Las transformaciones realizadas, por ejemplo, pocas veces se hacen en presencia de profesionales capacitados, lo que debilita y perjudica la estructura y la estética de los inmuebles.

De la totalidad de inmuebles, tanto los registrados como los inventariados, tan solo un $15 \%$ de ellos poseen declaratoria patrimonial. Este hecho muestra cómo todavía le falta a nuestro

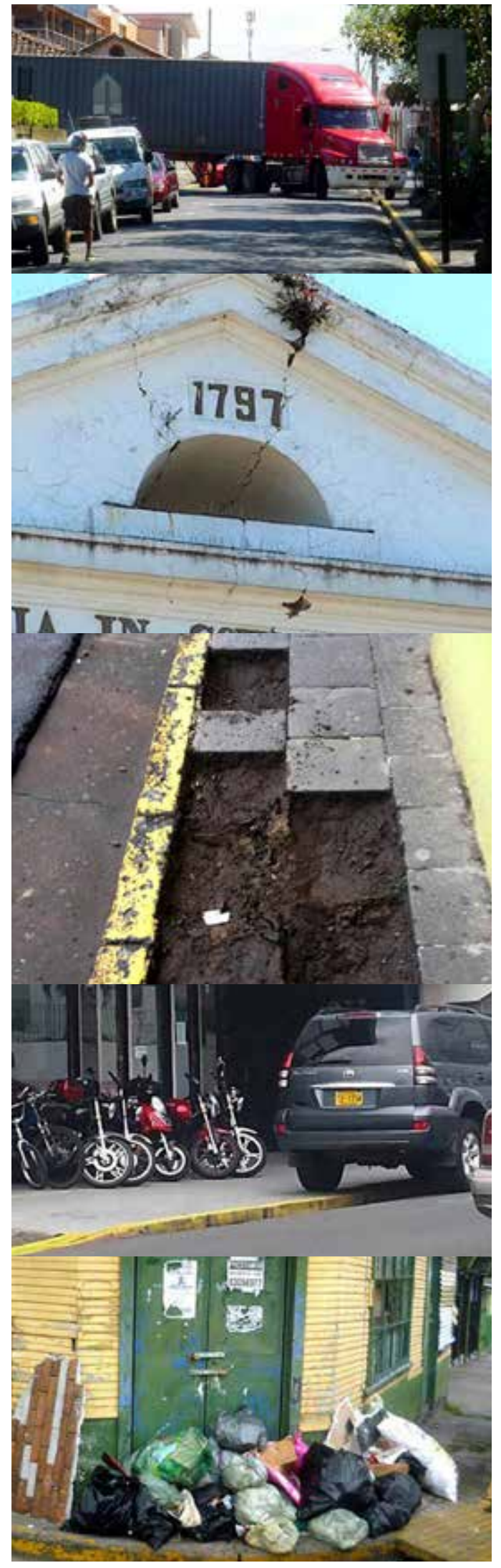

Ilustración 3.

Problemas que afectan los flujos viales $y$ peatonales. 


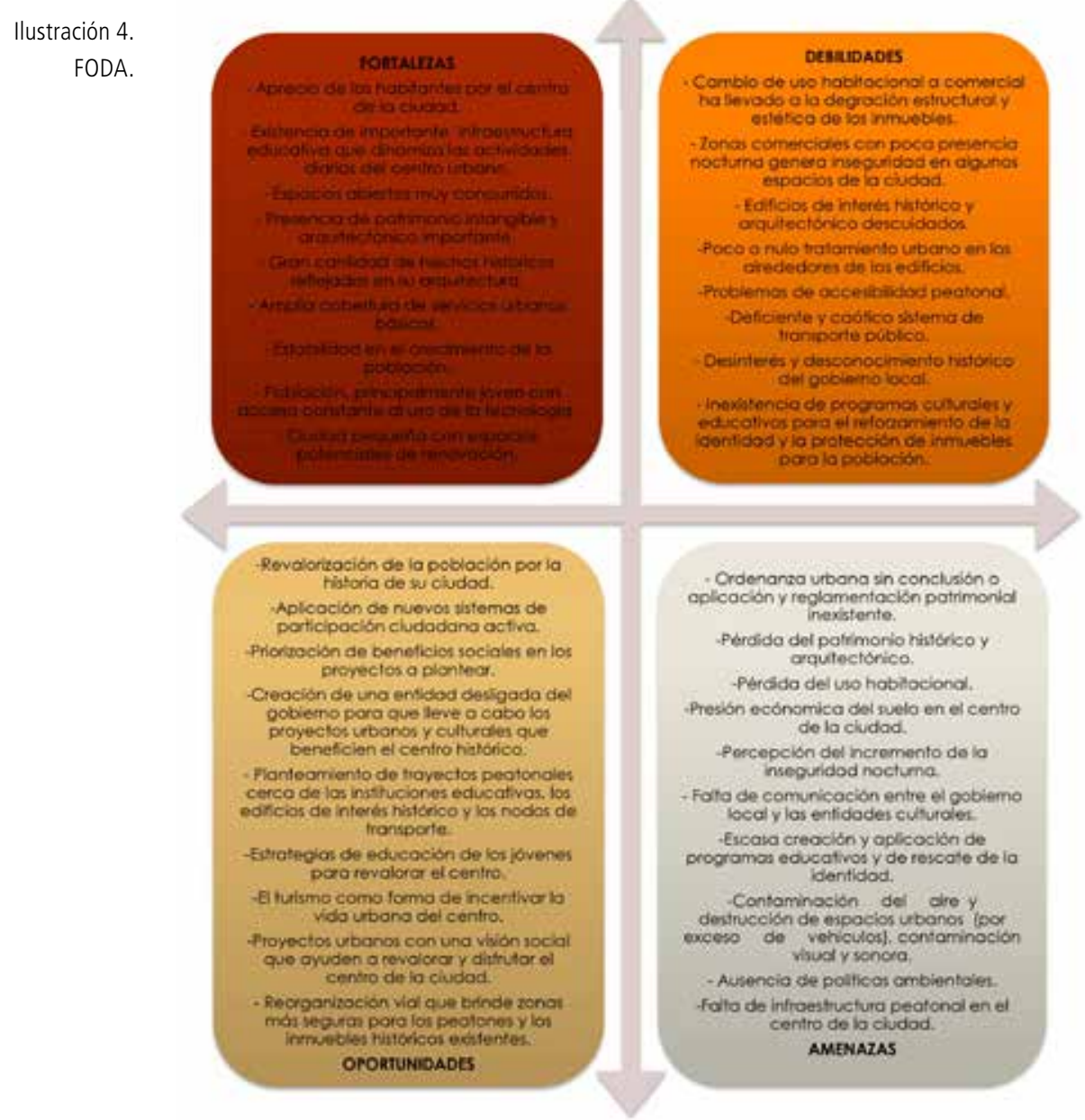

país educación y apoyo para las instituciones que se encargan del patrimonio cultural y arquitectónico.

Proteger todos los inmuebles que puedan ser significativos sería una tarea imposible para las autoridades, sin embargo, con el apoyo adecuado de la ciudadanía podrían redoblar esfuerzos, abarcar mayores zonas y aplicar otras estrategias de protección.

Asimismo, es importante destacar que los planes de protección pueden llegar a representar una herramienta integral de acciones para poner en práctica, siempre que se apliquen bajo la supervisión del gobierno local, además de que se planteen con base en estudios rigorosos como los que las instituciones y los profesionales pueden generar. Esto permitiría proteger las zonas urbanas históricas como conjuntos, sin la necesidad de declarar uno a uno los inmuebles, de forma tal que se dejaría esta tarea solo para las propiedades más relevantes o en mayor peligro.

\section{Planteamiento de intervenciones urbanas y arqui- tectónicas}

En la sección de propuestas se realiza una síntesis de la situación urbana. Esta indica que el centro histórico de la ciudad de Heredia es una zona que se encuentra casi en su totalidad construida. Además, se demuestra que la movilidad peatonal en el centro de la ciudad de Heredia es bastante limitada: las condiciones de las aceras no son buenas y en algunos sectores son casi inexistentes.

El carácter habitacional de esta ciudad ha sido reemplazado por uno comercial. Este tipo de cambio en el paisaje se debe controlar en las áreas urbanas históricas o perderán importantes valores de conjunto.

Entre los inmuebles analizados en Heredia, al menos un $50 \%$ ha cambiado su uso y muchos, lamentablemente, han sido destruidos para instalar en su lugar parqueos o inmuebles con poco valor arquitectónico. 
La identidad de un pueblo y su aprecio por la ciudad es una de las herramientas más fuertes con las que se puede contar para la salvaguardia del patrimonio construido. Por ello, para controlar estos cambios es necesaria una serie de medidas, no solo urbanas sino también educativas.

La ciudad es un elemento cambiante y responde a las acciones que en ella se generan. Entender el comportamiento de los agentes urbanos permite brindar un diagnóstico de la dinámica urbana y eso, aunado al comportamiento e importancia de las zonas e inmuebles estudiados, permite obtener las estrategias necesarias para la protección del centro histórico.

A continuación se presenta una tabla de Fortalezas, Oportunidades, Debilidades y Amenazas que permiten comprender en su totalidad el estado general de la zona urbana histórica y sus posibilidades de acción.

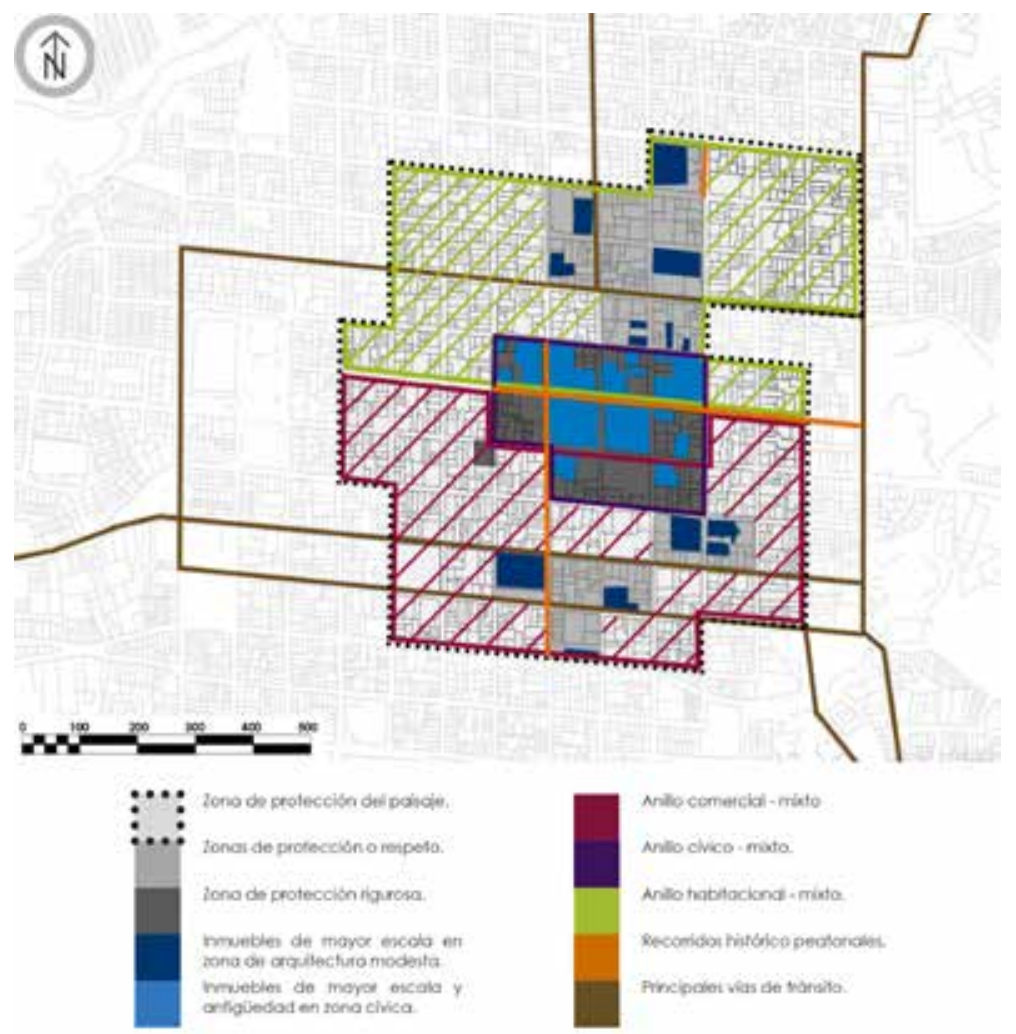

llustración 5. Propuesta de organización y lineamientos de acción urbana.

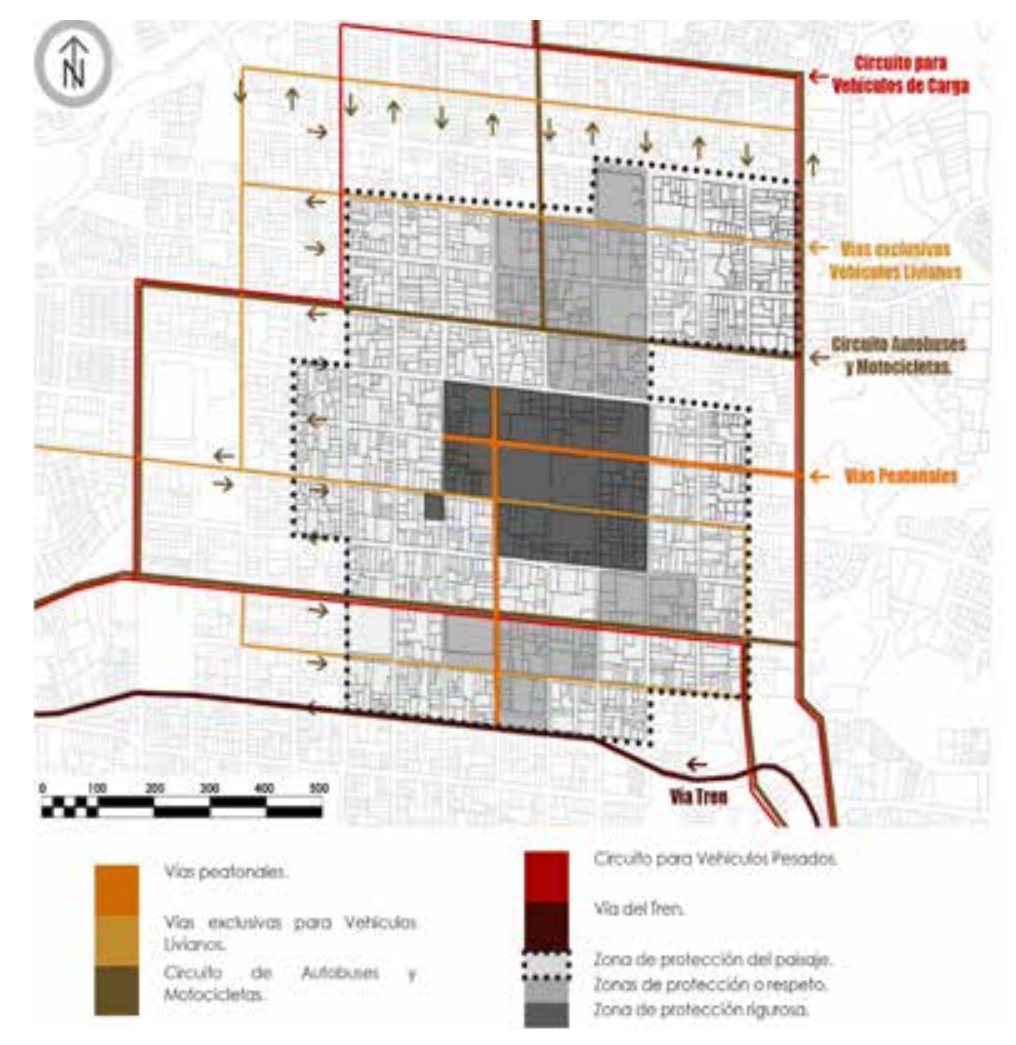

Ilustración 6 .

Propuesta de

mejoramiento del sistema vial, transporte y peatonización. 
Ilustración 7.

Propuesta de protección y conservación del patrimonio histórico y arquitectónico. Ejemplos.
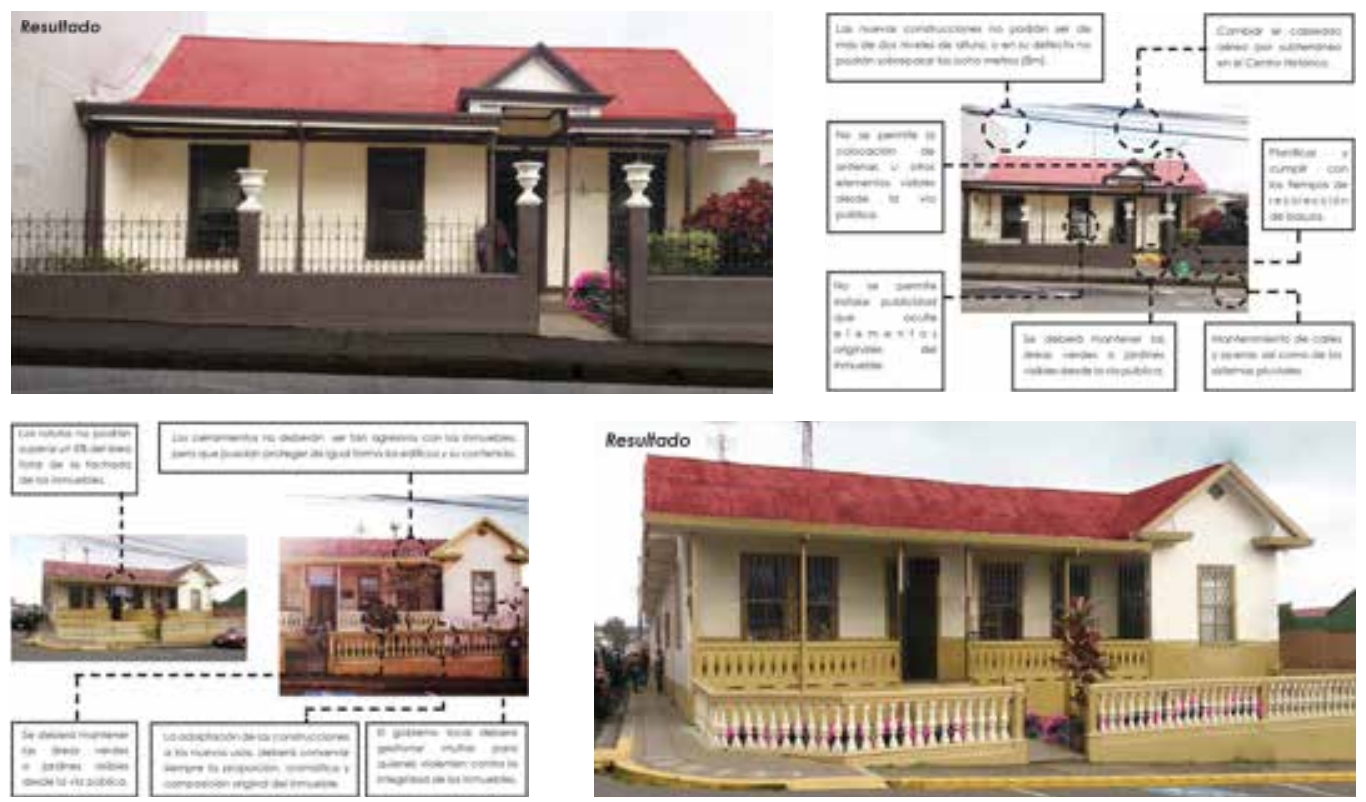

\section{Acción estratégica}

A continuación se describen las diez propuestas del plan de protección para el centro histórico de Heredia:

1. Propuesta de organización y lineamientos de acción urbana: mediante la reorganización de zonas según las jerarquías establecidas en el centro histórico de Heredia, se deben definir lineamientos para el fortalecimiento económico e infraestructural de la ciudad, en equilibrio con el Centro Histórico y sus limitantes espaciales.

2. Propuesta de mejoramiento del sistema vial, transporte y peatonización: ordenamiento de la vialidad con el fin de mejorar la circulación de los vehículos privados y los peatones en la ciudad de Heredia; además de mejorar el sistema de acceso y salida del transporte público según sus necesidades de ruta y conexión con otras ciudades.

3. Propuesta de protección y conservación del patrimonio histórico y arquitectónico, que incluye los siguientes lineamientos de acción: a) Urbanismo e imagen urbana y b) Arquitectura y estética. Los inmuebles históricos y sus espacios urbanos circundantes se deben incorporar a la vida diaria de la ciudad, mediante su puesta en valor, protección y conservación.

4. Propuesta de desarrollo cultural y fortalecimiento de la identidad que incluye: a) El diseño de una Imagen gráfica para el Centro Histórico de Heredia, y b) Programas de educación y difusión. Con esto se busca generar actividades y proyectos de difusión de la historia herediana y sus rasgos particulares, para fortalecer la identidad de esta comunidad. Además es necesario utilizar la educación como herramienta para que los ciudadanos revaloren la ciudad y su Centro Histórico.

5. Propuesta de servicios públicos y equipamiento urbano.

6. Propuesta de seguridad ciudadana.

7. Propuesta de calidad ambiental, en la que se incluye: a) Educación y difusión de información ambiental; b) Control de calidad; c) Recolección de residuos sólidos y limpieza; d) Infraestructura.

8. Propuesta de turismo cultural.

9. Propuesta de consolidación institucional. Las principales actividades que se establecen en este punto son: a) Acción y compromiso técnico; b) Comunicación y difu- 
sión; c) Educación y capacitación; d) Mediación y participación.

10. Gestión y permanencia: este tema es de especial importancia ya que es imperativo que la Oficina de Gestión planteada en este proyecto, sirva siempre como mediadora entre todas las instituciones participantes de los cambios urbanos, con el fin de llegar al necesario equilibrio que necesita el Centro Histórico y toda la ciudad de $\mathrm{He}$ redia.

\section{Conside- raciones finales}

$\begin{array}{cc}- \text { Toda } & \text { zona } \\ \text { urbana } & \text { debe }\end{array}$ conservar una parte de su historia para crecer sin perderse a sí misma. Es posible generar las modificaciones que la ciudad necesita para convertirla en un ejemplo de cambio y de valorización de la identidad y protección de los inmuebles históricos.

- Las intervenciones en el espacio público deben
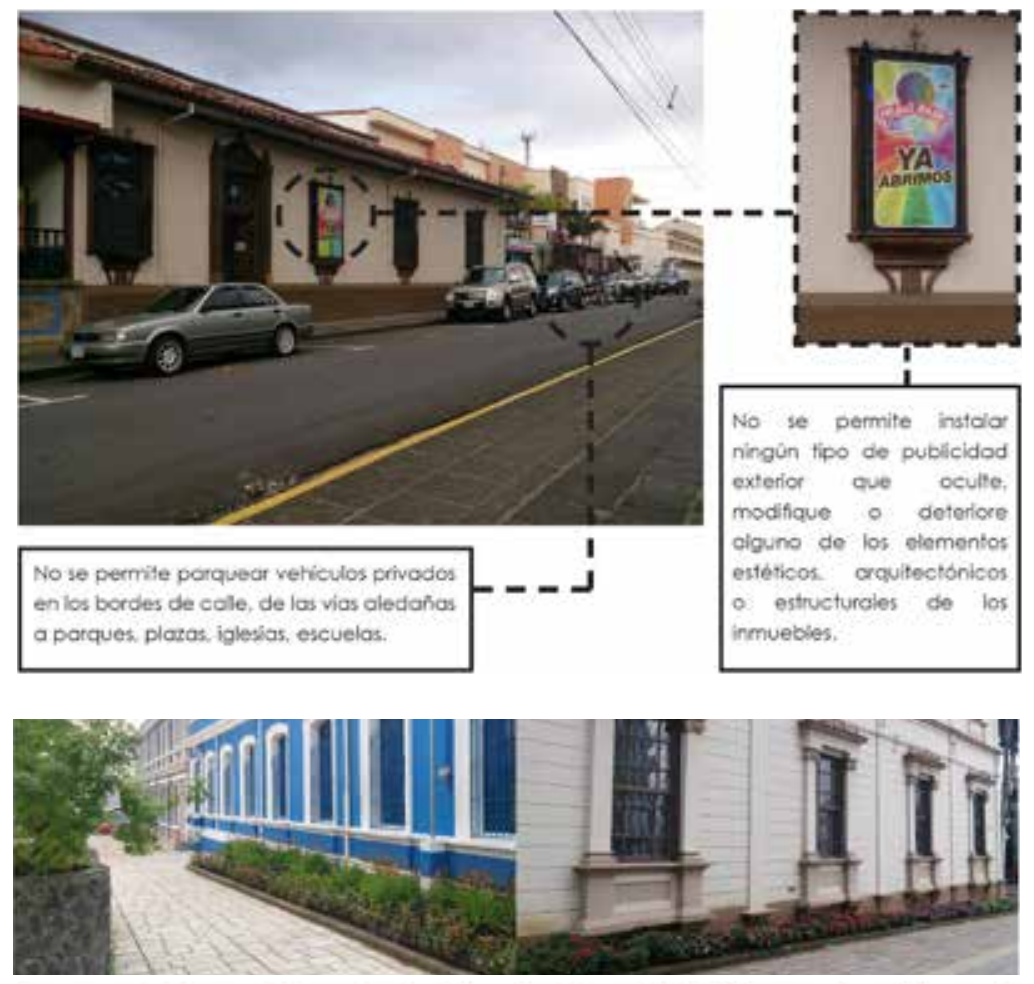

Es recomendoble crear jordines en los alrededores de los inmuebles históricos paro hocerle honor a la "Cludad de la Flares", asi ccmo crear una barrera natural entre el usuario y en inmueble. Se le debe dar mantenimiento constante, tol como indica la propuesto de coidad ambiental para evitor que el ogua. la suciedad o los animales dañen el inmueble.
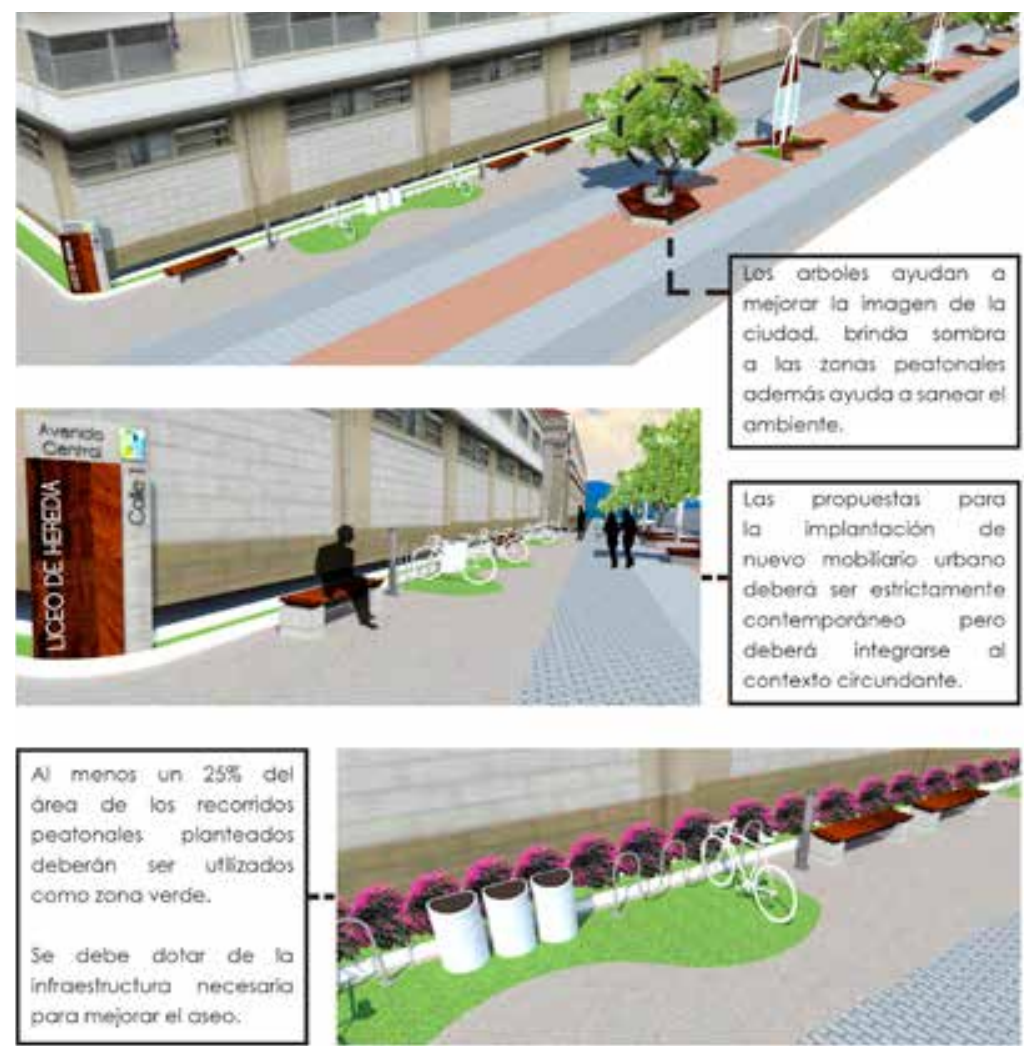

llustración 8.

Propuesta de protección y conservación del patrimonio histórico y arquitectónico. Ejemplos. 


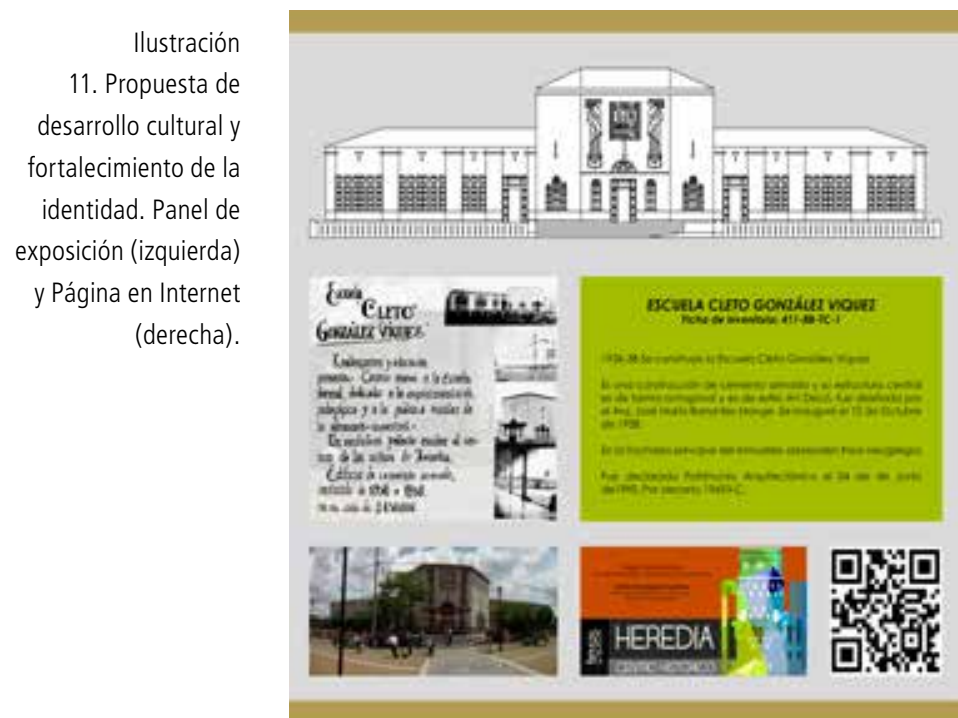

ser una de las prioridades por realizar. Toda intervención en el Centro Histórico de Heredia tiene que ser respetuosa de las características y escala de los inmuebles históricos, además de brindar siempre un beneficio social para el bienestar de la comunidad.

- Heredia creció como un núcleo urbano principalmente habitacional. Por ello debe incentivarse, en la medida de lo posible, recuperar estas funciones.

- Los principales detractores de la conciencia urbana y del equilibrio son la inexistencia de una ordenanza urbana y la falta de una comunicación más fluida y constante entre instituciones y comunidad.

- Todo movimiento en favor del cambio empieza y termina con la comunidad. Solo el pueblo puede darle al Centro Histórico el lugar que se merece en su memoria y en la ciudad.

“Heredianos: honrad siempre el pasado, porque el provenir se apoya y se alimenta en él. La ciudad vivirá perpetuamente honrada y cada vez será más grande y bella si conservamos la riqueza de esa herencia espiritual".

Luis Dobles Segreda.
Ilustración

11. Propuesta de desarrollo cultural y fortalecimiento de la identidad. Panel de exposición (izquierda) y Página en Internet (derecha).

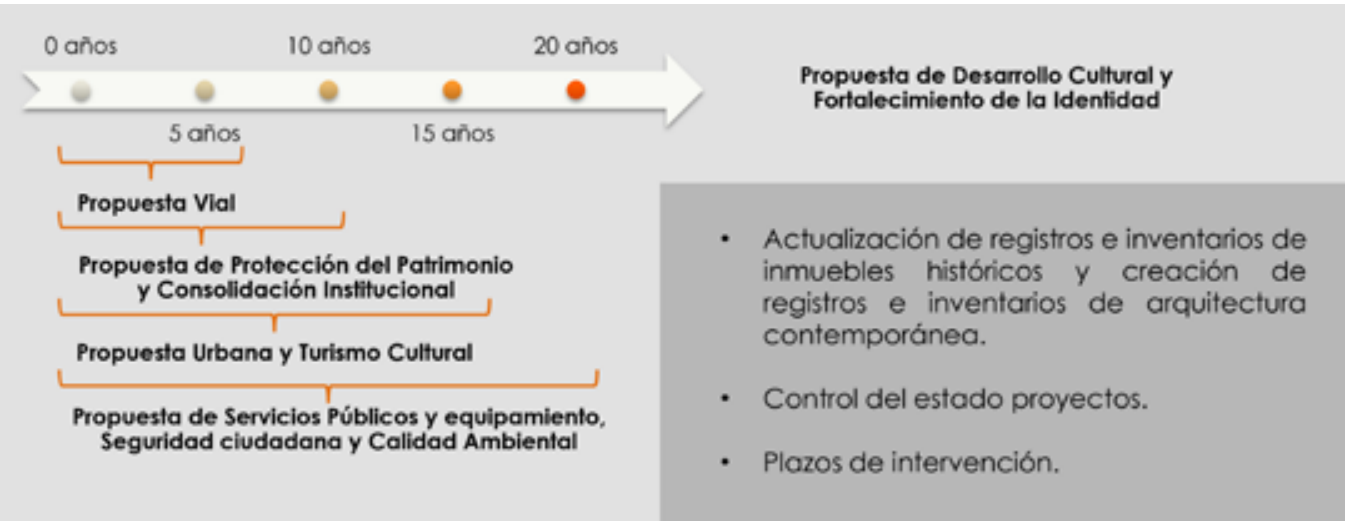




\section{Referencias}

- Asamblea Legislativa de la República de Costa Rica. (1995). Ley 7555-Ley de Patrimonio Histórico Arquitectónico de Costa Rica. La Gaceta. N¹99. San José: viernes 20 de octubre de 1995.

- Castro Elizondo, Angie (2014). Análisis de edificaciones de interés culturalarquitectónico del distrito central de Heredia: Plan de protección de una zona urbana histórica. Tesis para optar por el grado de Licenciatura en Arquitectura. San José: Instituto Tecnológico de Costa Rica, Escuela de Arquitectura y Urbanismo. Disponible en Internet en: https://issuu.com/angiecastro/docs/tesis_angie_castro

- Ellenberg, Ludwig. (1984). "El plano de la ciudad de Heredia". Revista geográfica de América Central. N 19-20. Heredia: pp. 247-254.

- Meléndez Chaverri, Carlos. (1993). Añoranzas de Heredia. Heredia: Editorial de la Universidad Nacional.

- $\quad$ Presidente de la República y Ministro de Cultura, Juventud y Deportes. (2005). Decreto $\mathrm{N}^{\circ} 32749-\mathrm{C}$ Reglamento compilado a la Ley $\mathrm{N}^{\circ} 7555$. San José: La Gaceta N²19-Lunes 14 de Noviembre del 2005.

- Rodríguez Argüello, Percy (1998). 185 años de la creación del ayuntamiento de Heredia: 1813-1998. Heredia: Municipalidad de Heredia.

- Secretaría Plan Nacional de Desarrollo Urbano. (2013). Plan GAM 2013. San José: Presidencia de la República - Consejo Nacional de Planificación Urbana.

\section{Acuerdos internacionales}

- Carta de Atenas, 1931.

- Carta de Urbanismo Moderno, 1934.

- Convención de la Haya, 1956.

- Congreso de Gubbio, 1960.

- Carta de Venecia, 1964.

- Normas de Quito, 1967.

- Carta del Restauro, 1972.

- Carta de Burra, 1981.

- Carta de Washington, 1987. 
